Prehospital care

\section{Pre-hospital emergency care in Ireland}

G Bury of those co-operatives in providing emergency care is variable; in some areas, close dispatch and care links exist between co-operatives and ambulance services, while in other areas, the services are quite distinct. ${ }^{6}$ The Medical Emergency Responders Integration and Training (MERIT) Project is a 2005 initiative by CICS funded by PHECC and the Department of Health and Children, which is exploring innovative mechanisms to link all of the relevant providers. Ireland has had no equivalent to the UK BASICS organisations; MERIT may well see the development of a professional and contractual system of support by medical practitioners for the ambulance service, but in the context of evidence based control systems and support mechanisms ranging from telephone advice to attendance at all agreed incidents.

Ireland's developing services are actively engaged in ensuring that standards, organisation, and integration of pre-hospital emergency care continue to improve. The opportunity to learn lessons from other systems and to contribute to the developing evidence base for high quality care is an important component of that development.

Emerg Med J 2005;22:893.

doi: $10.1136 / \mathrm{emj} .2005 .031591$

Correspondence to: Professor G Bury, General Practice, University College Dublin Coombe Healthcare Centre, Dublin 8, Ireland; gerard. bury@ucd.ie

Accepted for publication 11 October 2005 and collaboration between ambulance services, general practitioners, training bodies, and academic institutions.

The Centre for Immediate Care Services (CICS) at University College Dublin has worked with the ICGP and others to provide immediate care training in cardiac and trauma emergencies for many years. ${ }^{5}$ Approximately 400 one day places are provided each year and a large proportion of Ireland's 2500 general practitioners have attended at least one course in the past decade. Much of Ireland's population lives in rural or remote areas; the development of a dozen out of hours cooperatives since 1998 has brought significant improvements to the care of those populations and to the working lives of the many GPs who participate. However, the role

\section{REFERENCES}

1 Department of Health and Children. Report of the National Task Force On Medical Staffing, 2003.www.dohc.ie.

2 Department of Health and Children. Building healthier hearts: the report of the Cardiovascular Health Strategy Group 1999.

3 Department of Health and Children. Feasibility study on a helicopter emergency medical service for the island of Ireland 2004.

4 Pre-Hospital Emergency Care Council. www.phecc.ie.

5 Murphy AW, Bury G, Dowling J, et al. The teaching of immediate cardiac and trauma care to general practitioners in a skills-based outreach format: an assessment in terms of information gain. Med Educ 1999:33:774-6.

6 Bury G, Janes D, Dowling J. General practice outof-hours co-operatives in Ireland-emergency service or not? Ir J Med Sci 2005; 174:47-52. 